\title{
Systemic low-grade inflammation in siblings of type 2 diabetic patients
}

\author{
Yousef Rasmi $^{\mathrm{a}, \mathrm{b}, *}$, Mohammad Golizadeh ${ }^{\mathrm{c}}$, Neda Valizadeh ${ }^{\mathrm{d}}$, Masoud Saleh-Moghaddam $^{\mathrm{c}}$ \\ a Cellular and Molecular Research Centre, Urmia University of Medical Sciences, Urmia, Iran \\ b Department of Biochemistry, Faculty of Medicine, Urmia University of Medical Sciences, Urmia, Iran \\ c Department of Biology, Faculty of Sciences, Mashahd Payame Noor University, Mashhad, Iran \\ d Department of Endocrinology, Faculty of Medicine, Urmia University of Medical Sciences, Urmia, Iran
}

*Corresponding author, e-mail: rasmiy@umsu.ac.ir

Received 1 Sep 2012

Accepted 19 Mar 2014

\begin{abstract}
Chronic low-grade inflammation is involved in the development of diabetes mellitus type 2 (DMT2). Because of genetic inheritance, first-degree relatives of DMT2 patients are at increased risk of developing this metabolic disorder. We aimed to investigate the association of inflammation in the development of DMT2 in siblings of DMT2 patients. Twenty seven DMT2 patients and 27 healthy individuals without a family history of DMT2 were enrolled. Plasma levels of the high sensitive C-reactive protein (hs-CRP), tumour necrosis factor- $\alpha$ (TNF- $\alpha$ ), interleukin-6 (IL-6), and fibrinogen (FIB), as inflammatory factors were assessed in all individuals. Levels of hs-CRP, TNF- $\alpha$, IL-6, and FIB were significantly higher in DMT2 patients than in their siblings. Furthermore, all marker levels were found to be significantly higher in the siblings group than in healthy controls. Siblings of DMT2 patients are then at higher risk for DMT2 than healthy controls. Systemic inflammatory abnormalities may play an important role in the development of diabetes mellitus in siblings via endothelial dysfunction.
\end{abstract}

KEYWORDS: first-degree relative, diabetes, C-reactive protein, cytokines

\section{INTRODUCTION}

Diabetes is recognized as one of the leading cause of morbidity and mortality. The incidence of diabetes mellitus type 2 (DMT2) is increasing worldwide. It is estimated that by the year of 2025 , the number of people with diabetes will increase to more than twice compared to the year $2000^{1}$. DMT2 is associated with increased blood concentrations of inflammatory markers of the acute-phase proteins, including high sensitive C-reactive protein (hs-CRP), serum sialic acid, fibrinogen (FIB), and plasminogen activator inhibitor- $\mathrm{I}^{2-7}$. The acute phase proteins are synthesized in the liver, stimulated by cytokines. Three of the most important pro-inflammatory cytokines are C-reactive protein, tumour necrosis factor-alpha (TNF- $\alpha$ ), and interleukin-6 (IL-6), all of which have been implicated in atherogenesis ${ }^{7,8}$. Chronic inflammatory processes can induce a chronic increase of IL- 6 and TNF- $\alpha$ and thus turn the acute phase reaction into a chronic perpetuating state with increased levels of FIB $^{9}$. Elevation of FIB levels are more common in diabetic than in non-diabetic patients ${ }^{10}$. It is, therefore, suggested that chronic inflammation may represent a triggering factor in the origin of the metabolic syndrome, and eventually diabetes mellitus disease $^{4}$.

Due to a mixture of genetic inheritance and adoption of the family lifestyle, first-degree relatives (FDR) of patients diagnosed with diabetes mellitus are at increased risk of developing the disease. In addition to the insulin resistance found in young FDR ${ }^{11,12}$, family studies have revealed that FDR of individuals with DMT2 are about 3 times more likely to develop the disease than individuals without a positive family history of the disease ${ }^{13}$. It seems important therefore to verify whether a pro-inflammatory state is present in these subjects. These findings are the basis of our study to verify whether circulating concentrations of the cytokines and acute-phase proteins including TNF- $\alpha$, IL-6, hs-CRP, and FIB are different between siblings of DMT2 patients and individuals without a family history of DMT2.

\section{MATERIALS AND METHODS}

\section{Subjects}

Of the 200 patients with DMT2 who were examined by an endocrinologist, at the Department of Endocrinology, Urmia University of Medical Sciences, 
Table 1 Demographic and clinical characteristics of controls, siblings, and DMT2 patients.

\begin{tabular}{|c|c|c|c|c|c|c|}
\hline \multirow[t]{2}{*}{ Parameters } & \multirow{2}{*}{$\begin{array}{c}\text { Control } \\
(n=27)\end{array}$} & \multirow{2}{*}{$\begin{array}{c}\text { Sibling } \\
(n=28)\end{array}$} & \multirow{2}{*}{$\begin{array}{c}\text { DMT2 } \\
(n=27)\end{array}$} & \multicolumn{3}{|c|}{$p$ value } \\
\hline & & & & Control versus sibling & Control versus DMT2 & Sibling versus DMT2 \\
\hline Sex (M:F) & $15: 12$ & $14: 14$ & $9: 18$ & 0.44 & 0.1 & 0.21 \\
\hline Age (year) & $44.9 \pm 8.0$ & $44.5 \pm 7.1$ & $48.5 \pm 6.8$ & 0.996 & 0.131 & 0.153 \\
\hline $\mathrm{BMI}\left(\mathrm{kg} / \mathrm{m}^{2}\right)$ & $28.8 \pm 4.4$ & $30.6 \pm 5.9$ & $28.6 \pm 3.6$ & 0.172 & 0.906 & 0.131 \\
\hline FBS (mg/dl) & $83.0 \pm 6.5$ & $90.0 \pm 7.8$ & $193 \pm 48$ & 0.384 & 0.0001 & 0.0001 \\
\hline
\end{tabular}

Urmia, Iran; 27 patients and their sibling(s) accepted to participate in the research. Each patient was asked whether any of her/his sibling(s) had diabetes or not as per the WHO criteria ${ }^{14}$. Then the importance of study was explained to those siblings who volunteer to participate. Finally. 28 siblings of DMT2 patients were enrolled. Twenty-seven healthy individuals without a family history of DMT2 that had recently been examined were enrolled as a control group.

\section{Exclusion criteria}

Subjects were carefully selected to exclude conditions that could interfere with hs-CRP, TNF- $\alpha$, IL-6, or FIB levels including coronary heart disease, smoking, hypertension, bronchial asthma, acute or chronic inflammatory diseases, autoimmune diseases, and medications like steroids and antipsychotic drugs.

\section{Anthropometric and blood pressure measurements}

The body weight and height of each subjects was measured in the morning. After 5 min of rest, the brachial systolic and diastolic blood pressure (SBP, DBP) was measured while the subjects remained seated.

\section{Blood collection}

Blood samples were taken before breakfast in the morning (between $8 \mathrm{AM}$ and $11 \mathrm{AM}$ ), after an 8$12 \mathrm{~h}$ overnight fast. Ten millilitres of venous blood sample were taken and were collected in plastic tubes containing heparin and then centrifuged at $1100 \mathrm{~g}$ for $10 \mathrm{~min}$. Plasma was separated, aliquoted, and stored at $-80{ }^{\circ} \mathrm{C}$ until analysis.

\section{Biochemical and immunoassays}

The hs-CRP was quantitatively determined by using the kit (Diagnostic Biochem Canada Inc.). The sensitivity and the established standard curve for hs-CRP were $10 \mathrm{ng} / \mathrm{ml}$ and 0-10 $000 \mathrm{ng} / \mathrm{ml}$, respectively. Plasma concentration of TNF- $\alpha$ and IL-6 was determined by a solid phase sandwich enzymelinked immunosorbent assay (ELISA, eBioscience). The sensitivity and the established standard curve for
TNF- $\alpha$ were $5 \mathrm{pg} / \mathrm{ml}$ and $23-1500 \mathrm{pg} / \mathrm{ml}$, respectively, whereas for IL-6, the sensitivity was $0.92 \mathrm{pg} / \mathrm{ml}$, and the standard curve was linear in the range of 1.56$100 \mathrm{pg} / \mathrm{ml}$. In addition, FIB was estimated by Clauss method $^{15}$ using kit (Mahsayaran Co., Iran). A glucose oxidase method was employed to measure fasting blood sugar (FBS).

\section{Statistical analysis}

All analyses were performed using SPSS/PC statistical program (version 18.0). Results are reported as the mean \pm SD. The differences between the groups were tested for significance by one-way ANOVA tests. Tukey's test was used as post hoc analysis as appropriate. Differences in proportions were tested using Pearson's chi squared test. The relation between variables was analysed by Pearson's correlation. Differences and correlations were considered significant at $p<0.05$.

\section{Research ethics}

The study protocol (No. 372-2011) was approved by Research Ethics Committee of Urmia Research Administration adopted from current version of declaration of Helsinki. All participants gave written consent.

\section{RESULTS}

Demographic and clinical characteristics of controls, siblings, and DMT2 patients is shown in Table 1. Duration of disease in DMT2 patients was $96 \pm 70$ month. Plasma FBS levels in DMT2 patients $(193 \pm 48 \mathrm{mg} / \mathrm{dl})$ versus siblings $(90.0 \pm 7.8 \mathrm{mg} / \mathrm{dl})$ and controls $(83.0 \pm 6.5 \mathrm{mg} / \mathrm{dl})$ showed significant differences ( $p=0.0001$, for all). FBS levels however were not statistically significant between siblings and healthy individuals ( $p=0.384)$, Table 1. Plasma levels of hs-CRP and FIB were significantly higher in DMT2 patients to their siblings (hs-CRP: $4.9 \pm 2.4$ versus $3.6 \pm 2.0 \mu \mathrm{g} / \mathrm{ml}, p=0.023$; FIB: $493 \pm 140$ versus $330 \pm 88 \mathrm{mg} / \mathrm{dl}, \quad p=0.0001$, respectively) and healthy controls (hs-CRP: $2.3 \pm 1.8 \mu \mathrm{g} / \mathrm{ml}$, $p=0.0001$; FIB: $216 \pm 76 \mathrm{mg} / \mathrm{dl}, p=0.0001)$. Also, 


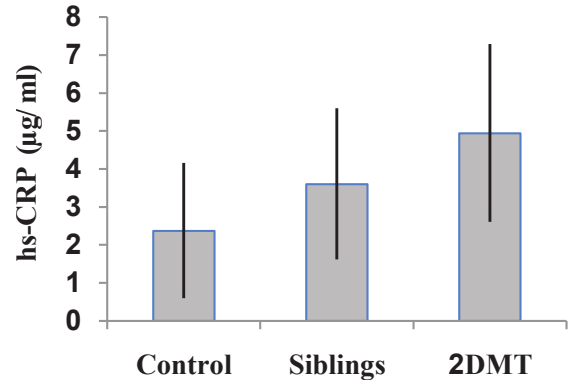

Fig. 1 Circulating hs-CRP levels in the plasma of DMT2 patients, in their siblings, and control subjects. Levels of hs-CRP were significantly higher in DMT2 patients, in their siblings when compared with control subjects $(p<0.05)$.

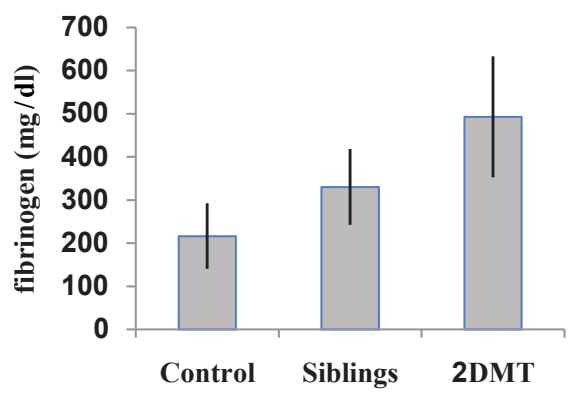

Fig. 2 Plasma FIB levels in DMT2 patients, in their siblings, and control subjects. Higher levels of FIB were found in DMT2 patients and their siblings when compared to control group $(p<0.05)$.

the hs-CRP and FIB levels were found to be significantly higher in siblings group than in healthy controls ( $p=0.032$ and 0.005 , respectively) (Figs. 1 and 2). Plasma TNF- $\alpha$ and IL-6 concentration in patients group were significantly higher than those in their siblings (TNF- $\alpha$ : $239 \pm 43 \mathrm{pg} / \mathrm{ml}$ versus $152 \pm 31 \mathrm{pg} / \mathrm{ml}, p=0.0001 ; \mathrm{IL}-6: 23 \pm 22 \mathrm{pg} / \mathrm{ml}$ versus $11.2 \pm 7.8 \mathrm{pg} / \mathrm{ml}, p=0.0001$, respectively) and healthy controls (TNF- $\alpha$ : $47 \pm 27 \mathrm{pg} / \mathrm{ml}, p=0.0001$; IL-6: $3.9 \pm 2.3 \mathrm{pg} / \mathrm{ml}, p=0.0001$, respectively). In addition, the TNF- $\alpha$ and IL- 6 levels were found to be significantly higher in siblings group than in healthy controls ( $p=0.0001$ and 0.049 , respectively) (Figs. 3 and 4).

Significant correlations were detected between hs-CRP and TNF- $\alpha$ with FBS in healthy individuals $(r=0.773, p=0.0001 ; r=0.508, p=0.01$, respectively). Levels of hs-CRP showed significant relationship with FBS $(r=0.655, p=0.0001)$, and BMI $(r=0.419, p=0.037)$ in siblings. The relationship between hs-CRP, BMI and FIB levels was observed in diabetic patients $(r=0.464, p=0.02 ; r=0.570$, $p=0.026$, respectively).

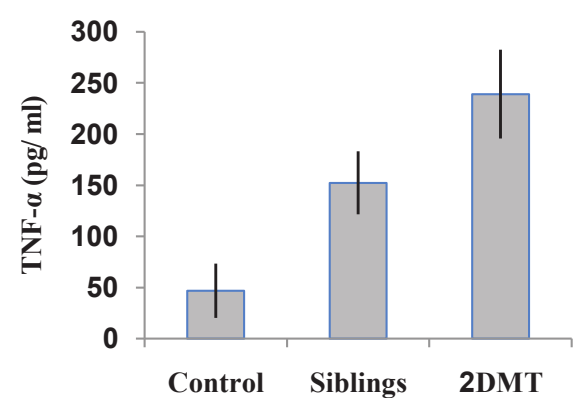

Fig. 3 Levels of plasma TNF- $\alpha$ in DMT2 patients, in their siblings, and control subjects. Levels of TNF- $\alpha$ were significantly higher in DMT2 patients, in their siblings when compared with control subjects $(p<0.05)$.

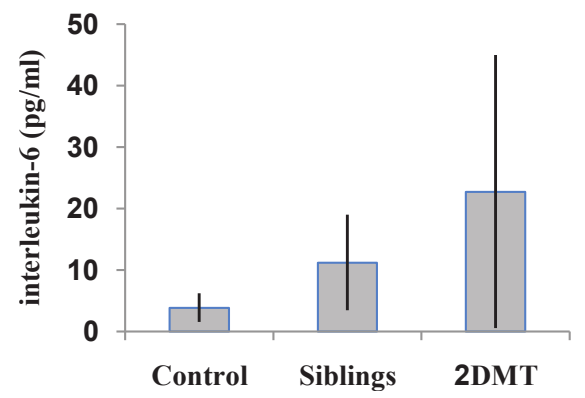

Fig. 4 Circulating IL-6 values in the plasma of DMT2 patients, in their siblings, and control subjects. Levels of IL-6 were significantly higher in DMT2 patients, in their siblings when compared with control subjects $(p<0.05)$.

\section{DISCUSSION}

Inflammatory markers have emerged as independent predictors of metabolic disorders such as diabetes mellitus. In past few years, many studies have been focused on hs-CRP, as a marker of low-grade inflammation ${ }^{16}$. Indeed, other inflammation markers such as TNF- $\alpha$ and IL- 6 have been found to be increased in diabetes ${ }^{17,18}$. In addition, elevation of FIB levels and impaired fibrinolysis are more common in diabetic patients than non-diabetic subjects ${ }^{19}$. The major aim of the current study was to investigate the inflammatory status in siblings of diabetic patients who have a considerably increased risk for development of the disease later in life. These individuals showed a low-grade inflammation in our study compared to normal people without a family history of disease. Thus increased circulating levels of hs-CRP, TNF- $\alpha$, IL- 6 , and FIB are present in non-diabetic FDR as well as their affected siblings. These data clearly indicated that augmented cytokines production is prevalent in healthy siblings of diabetic patients. It seems that in DMT2, there is an ongoing cytokine-mediated acute-phase response (part of a wide-ranging activation of innate 
immunity), and this is closely involved in the pathogenesis of this metabolic disorder ${ }^{20,21}$. Our findings of a significant association between hs-CRP and BMI in siblings and patients is in agreement with previous results showing BMI was the parameter most strongly correlated with hs-CRP concentration ${ }^{22}$; however, the role of adipose tissue as a possible cause of the chronic inflammatory conditions in patients and siblings requires further study. A few studies have evaluated the association between plasma hs-CRP and FIB levels and the development of atherosclerosis in diabetic patients. The study of Hashimoto et $\mathrm{al}^{23}$ reports that an elevated concentration of hs-CRP and FIB is positively correlated with atherosclerosis in subjects with a low-grade inflammation. In the current study we found that hs-CRP and FIB concentrations were statistically higher in siblings than healthy subjects, therefore it could be hypothesized that differences in these inflammatory factors may explain a low-grade inflammation in siblings which may be a risk factor for DMT2. In another study, Ozkaya et $\mathrm{al}^{24}$ demonstrated the presence of a significant difference for hs-CRP levels between FDR of DMT2 and healthy subjects. Similarly another study in Denmark revealed a higher levels of hs-CRP in FDR groups than in controls ${ }^{25}$. In addition, no significant differences were found on age and BMI in mentioned studies and our results are in agreement with these findings.

There was a report that TNF- $\alpha$ was significantly higher in siblings and parents of insulin dependent diabetes mellitus compared to the appropriate control group ${ }^{26}$. Several studies have shown that hs-CRP levels is associated with blood pressure ${ }^{27}$, a result different from that observed in our study. An association between hs-CRP levels and FBS was also reported ${ }^{28}$ and confirmed by Tracy et $\mathrm{al}^{29}$. We confirmed this relationship between hs-CRP levels and FBS in siblings and patients. Our data supports the opinion that chronic subclinical inflammation could be one of the components of DMT2 $2^{30,31}$. There are however several possible explanations for these findings ${ }^{30}$. First, chronic inflammation may act as an initiating factor in the development of the eventually DMT2, as proposed by Pickup and Crook ${ }^{4}$. In their theory, stimuli such as age and over-nutrition in genetically predisposed subjects would result in increased proinflammatory cytokines such as IL- 6 and TNF- $\alpha$. The acute-phase response induced by pro-inflammatory cytokines could finally lead to insulin resistance and diabetes. This theory is supported with a recent report that elevated that levels of hs-CRP and IL-6 predict the development of DMT2 in healthy middleaged women ${ }^{32}$. In a study by Choi et al ${ }^{33}$, IL-6 levels were not correlated with any component of the DMT2 patients, while TNF- $\alpha$ levels were correlated only with haemoglobin, haematocrit and some lipid profiles. The correlation between IL-6 and anthropometric measurements was not significant in our study, and there was a correlation between TNF- $\alpha$ with BMI in siblings, and TNF- $\alpha$ with FBS in controls.

Our study should be interpreted within the context of its possible limitations; we cannot exclude with certainty that there is a protective effect from other factors. Also, the number of subjects in the study was low.

\section{CONCLUSIONS}

In summary, our study shows elevated levels of inflammatory factors hs-CRP, TNF- $\alpha$, IL-6, and FIB in siblings than controls, and concentration of all these factors was higher in DMT2 than siblings and control groups. We have also demonstrated that healthy siblings of subjects with DMT2 exhibit over production of a range of cytokines which have been implicated in the development of this metabolic disorder. We have clearly shown that many of inflammatory abnormalities involved in diabetogenesis are shared by healthy family members.

Acknowledgements: This work was derived from an MSc thesis in Biochemistry and supported by a research grant from the Urmia University of Medical Sciences, Iran.

\section{REFERENCES}

1. Wild S, Roglic G, Green A, Sicree R, King H (2004) Global prevalence of diabetes: estimates for the year 2000 and projections for 2030. Diabetes Care 27, 1047-53.

2. Yudkin JS (1995) Coronary heart disease in diabetes mellitus: three new risk factors and a unifying hypothesis. J Intern Med 238, 21-30.

3. Pickup JC, Mattock MB, Chusney GD, Burt D (1997) NIDDM as a disease of the innate immune system: association of acute-phase reactants and interleukin-6 with metabolic syndrome X. Diabetologia 40, 1286-92.

4. Pickup JC, Crook MA (1998) Is Type II diabetes mellitus a disease of the innate immune system? $\mathrm{Di}$ abetologia 41, 1241-8.

5. Bastard JP, Piéroni L, Hainque B (2000) Relationship between plasma plasminogen activator inhibitor 1 and insulin resistance. Diabetes Metabol Res Rev 16, 192-201.

6. McMillan DE (1989) Increased levels of acute-phase serum proteins in diabetes. Metabolism 38, 1042-6.

7. Cesari M, Penninx BW, Newman AB, Kritchevsky SB, Nicklas BJ, Sutton-Tyrrell K, Rubin SM, Ding $\mathrm{J}$, et al (2003) Inflammatory markers and onset of 
cardiovascular events: results from the Health $\mathrm{ABC}$ study. Circulation 108, 2317-22.

8. Koukkunen H, Penttilä K, Kemppainen A, Halinen M, Penttilä I, Rantanen T, Pyörälä K (2001) C-reactive protein, fibrinogen, interleukin- 6 and tumour necrosis factor- $\alpha$ in the prognostic classification of unstable angina pectoris. Ann Med 33, 37-47.

9. Gabay C, Kushner I (1999) Acute-phase proteins and other systemic responses to inflammation. New Engl J Med 340, 448-54.

10. Neri S, Bruno CM, Raciti C, D'Angelo G, D'Amico R, Cristaldi R (1994) Alteration of oxide reductive and haemostatic factors in type 2 diabetics. $J$ Intern Med 236, 495-500.

11. Kriketos AD, Greenfield JR, Peake PW, Furler SM, Denyer GS, Charlesworth JA, Campbell LV (2004) Inflammation, insulin resistance, and adiposity: a study of first-degree relatives of type 2 diabetic subjects. Diabetes Care 27, 2033-40.

12. Vaag A, Henriksen JE, Beck-Nielsen H (1992) Decreased insulin activation of glycogen synthase in skeletal muscles in young nonobese Caucasian firstdegree relatives of patients with non-insulin-dependent diabetes mellitus. J Clin Investig 89, 782-8.

13. Florez JC, Hirschhorn J, Altshuler D (2003) The inherited basis of diabetes mellitus: implications for the genetic analysis of complex traits. Annu Rev Genom Hum Genet 4, 257-91.

14. World Health Organization (1980) WHO Expert Committee on Diabetes Mellitus: Second Report. World Health Organization Technical Report Series, No. 646. World Health Organization, Geneva, Switzerland.

15. Clauss A (1957) Quick method to estimate fibrinogen by a functional clotting assay. Acta Haematol 19, 237-46.

16. Castell JV, Gómez-Lechón MJ, David M, Fabra R, Trullenque R, Heinrich PC (1990) Acute-phase response of human hepatocytes: regulation of acutephase protein synthesis by interleukin-6. Hepatology 12, 1179-86.

17. Bastard JP, Jardel C, Delattre J, Hainque B, Bruckert E, Oberlin F (1999) Evidence for a link between adipose tissue interleukin-6 content and serum C-reactive protein concentrations in obese subjects. Circulation 99, $2219 \mathrm{c}-22$.

18. Maruna P, Gürlich R, Fraško R, Haluzík M (2001) Serum leptin levels in septic men correlate well with C-reactive protein (CRP) and TNF-alpha but not with BMI. Physiol Res 50, 589-94.

19. Ernst E, Resch KL (1993) Fibrinogen as a cardiovascular risk factor: a meta-analysis and review of the literature. Ann Intern Med 118, 956-63.

20. Pickup JC (2004) Inflammation and activated innate immunity in the pathogenesis of type 2 diabetes. $D i$ abetes Care 27, 813-23.

21. Wellen KE, Hotamisligil GS (2005) Inflammation, stress, and diabetes. J Clin Investig 115, 1111-9.
22. Rexrode KM, Pradhan A, Manson JE, Buring JE, Ridker PM (2003) Relationship of total and abdominal adiposity with CRP and IL-6 in women. Ann Epidemiol 13, 674-82.

23. Hashimoto H, Kitagawa K, Hougaku H, Shimizu Y, Sakaguchi M, Nagai Y, Iyama S, Yamanishi H, et al (2001) C-reactive protein is an independent predictor of the rate of increase in early carotid atherosclerosis. Circulation 104, 63-7.

24. Ozkaya M, Sahin M, Cakal E, Gisi K, Bilge F, Kilinc M (2009) Selenium levels in first-degree relatives of diabetic patients. Biol Trace Elem Res 128, 144-51.

25. Sonne MP, Højbjerre L, Alibegovic AA, Vaag A, Stallknecht B, Dela F (2009) Impaired endothelial function and insulin action in first-degree relatives of patients with type 2 diabetes mellitus. Metabolism 58, 93-101.

26. Hussain MJ, Maher J, Warnock T, Vats A, Peakman M, Vergani D (1998) Cytokine overproduction in healthy first degree relatives of patients with IDDM. Diabetologia 41, 343-9.

27. Yudkin JS, Stehouwer CD, Emeis JJ, Coppack SW (1999) C-reactive protein in healthy subjects: associations with obesity, insulin resistance, and endothelial dysfunction: a potential role for cytokines originating from adipose tissue? Arterioscler Thromb Vasc Biol 19, 972-8.

28. Mendall MA, Patel P, Ballam L, Strachan D, Northfield TC (1996) C reactive protein and its relation to cardiovascular risk factors: a population based cross sectional study. Br Med J 312, 1061-5.

29. Tracy RP, Psaty BM, Macy E, Bovill EG, Cushman M, Cornell ES, Kuller LH (1997) Lifetime smoking exposure affects the association of C-reactive protein with cardiovascular disease risk factors and subclinical disease in healthy elderly subjects. Arterioscler Thromb Vasc Biol 17, 2167-76.

30. Festa A, D’Agostino R Jr, Howard G, Mykkänen L, Tracy RP, Haffner SM (2000) Chronic subclinical inflammation as part of the insulin resistance syndrome: the Insulin Resistance Atherosclerosis Study (IRAS). Circulation 102, 42-7.

31. Fröhlich M, Imhof A, Berg G, Hutchinson WL, Pepys MB, Boeing H, Muche R, Brenner H, Koenig W (2000) Association between C-reactive protein and features of the metabolic syndrome: a population-based study. Diabetes Care 23, 1835-9.

32. Pradhan AD, Manson JE, Rifai N, Buring JE, Ridker PM (2001) C-reactive protein, interleukin 6, and risk of developing type 2 diabetes mellitus. $\mathrm{J}$ Am Med Assoc 286, 327-34.

33. Choi KM, Lee J, Lee KW, Seo JA, Oh JH, Kim SG, Kim NH, Choi DS, Baik SH (2004) Comparison of serum concentrations of C-reactive protein, TNF- $\alpha$, and interleukin 6 between elderly Korean women with normal and impaired glucose tolerance. Diabetes Res Clin Pract 64, 99-106. 